\title{
PESONA KENANGAN YANG TAK TERLUPAKAN MELALUI PEMASARAN BERBASIS PENGALAMAN ALA AHADIAT HOTEL \& BUNGALOW, BANDUNG
}

\author{
Yenli Megawati \\ Manajemen, Universitas Bunda Mulia, Jakarta. \\ Alamat surel: yenli_m@yahoo.com \\ Novita \\ Manajemen, Universitas Bunda Mulia, Jakarta. \\ Alamat surel: novita@bundamulia.ac.id
}

\begin{abstract}
Bandung is a developing city that has a lot of attractions. One of them is the beauty of nature. Ahadiat Hotel \& Bungalows has a different concept to other hotel in Bandung. Located in Sukajadi which is just 10 kilometers from the center of city, Ahadiat Hotel \& Bungalow impressed of its uniqueness because it is out of the noise but still accessible to the city. This study investigates whether the experiential marketing effect on customer loyalty. Respondents in this study were 107 customers who stayed at Ahadiat Hotel \& Bungalow, Bandung. The results showed that the experiential marketing of Ahadiat Hotel \& Bungalow effect on customer satisfaction. And customer satisfaction affects customer loyalty to stayed at Ahadiat Hotel \& Bungalow, Bandung.
\end{abstract}

Keywords: experiential marketing, satisfaction, loyalty

\section{Pendahuluan}

Kota Bandung merupakan kota kembang yang memiliki sejuta pesona. Salah satu hal yang paling menonjol dari pesona kota Bandung adalah keindahan alamnya. Wisatawan nusantara dan mancanegara kini tidak hanya akan mengunjungi Denpasar saja ketika berkunjung ke Indonesia karena Bandung kini semakin bersinar di mata wisatawan. Berdasarkan hasil survei yang dirilis situs perjalanan wisata dunia TripAdvisor, Bandung merupakan tempat tujuan wisata yang paling dicari oleh wisatawan di Indonesia setelah Jakarta dan Bali (bisnis.com, 10 Juni 2014). Menurut survei independen yang dilakukan terhadap wisatawan nusantara dan mancanegara di situs jejaring sosial Facebook, Bandung menempati urutan pertama sebagai kota favorit di ASEAN, urutan kelima se-Asia Pasifik, dan urutan ke-21 dunia (CNN Indonesia, 10/02/2015). Popularitas Bandung juga semakin meningkat dengan adanya Konferensi Asia Afrika (KAA) pada tanggal 19-23 April 2015. Di Kota Kembang ini, wisatawan disuguhkan berbagai tempat wisata dan atraksi yang menarik. Tidak hanya itu, wisatawan juga dimanjakan dengan aneka sajian Tanah Pasundan yang menggugah selera. Bagi yang gemar belanja, Bandung juga menjadi satu kota yang menjadi surga belanja.

Popularitas Kota Bandung yang semakin menanjak sebagai salah satu pilihan tujuan wisata dimanfaatkan Pemerintah Kota Bandung untuk menggaet lebih banyak wisatawan. Dinas Kebudayaan dan Pariwisata menargetkan 5,6 juta wisatawan datang ke Kota Bandung pada tahun 2016. Dari jumlah tersebut, Dinas Pariwisata Kota Bandung membidik 1 juta wisatawan asing. Pada tahun 2015, tercapai target 5 juta wisatawan datang ke Bandung. Wisatawan yang datang ke Bandung didominasi warga negara Malaysia dan Singapura, mencapai target 500 ribu wisatawan asing. Tahun ini, ditargetkan untuk membidik wisatawan tidak hanya dari wilayah ASEAN tetapi juga Timur Tengah dan Amerika Latin (Tempo.co, 19/02/2016). Salah satu upaya untuk menggaet turis asing agar mau datang ke Bandung, Dinas Pariwisata menyiapkan banyak acara dan festival. Beberapa acara internasional seperti Asia African Carnival, konferensi musik, dan International Photo 
Competition akan dilaksanakan di tahun 2016.

Sebagai salah satu kota tujuan wisata, Kota Bandung juga ditunjang oleh berbagai fasilitas pendukung tempat wisata, seperti penginapan untuk memfasilitasi para wisatawan yang ingin lebih lama lagi menikmati pesona kota Bandung. Berdasarkan data dari Perhimpunan Hotel Restoran Indonesia (PHRI), sejak diresmikannya tol Cipularang, jumlah hotel di Kota Bandung meningkat dratis mencapai 470 hotel dengan hunian sebanyak $4.000-$ 5.000 kamar (kompasiana.com, 27/06/2015). Hal ini menyebabkan persaingan yang terjadi semakin ketat.

Pengelola usaha hotel di Kota Bandung saling berlomba-lomba untuk dapat menarik konsumen agar lebih memilih menginap di tempat mereka ketika berada di kota Bandung. Dalam melakukan persaingan, pengelola usaha harus memiliki keunggulan bersaing dengan melakukan strategi fokus kepada konsumen. Strategi yang sering dilakukan adalah strategi perang harga. Berdasarkan data dari situs Traveloka dan Agoda, selain menetapkan harga yang tinggi, hotel-hotel di Bandung juga ada yang banting harga sampai hanya Rp 70.000,- - Rp. 200.000,- per malam tanpa fasilitas. Selain strategi tersebut, strategi lain yang dapat dilakukan adalah memonitor pengalaman yang dirasakan dari kontak dengan penyedia jasa. Dalam pendekatan ini, pengelola usaha menciptakan produk dengan menyentuh panca indera konsumen, menyentuh hati dan merangsang pikiran konsumen. Jika produk dapat menyentuh nilai emosional konsumen secara positif maka dapat menjadi pengalaman tak terlupakan antara pengelola dan konsumen. Hal ini berpengaruh sangat baik bagi pengelola karena konsumen yang puas biasanya menceritakan pengalamannya menggunakan jasa suatu perusahaan kepada orang lain. Hal ini dapat digunakan sebagai sarana promosi gratis bagi pihak pengelola usaha (Gentille et al., 2007).

Dalam mencapai tujuan perusahaan, dibutuhkan suatu strategi untuk menarik minat para konsumen. Dalam pendekatan
Pemasaran berbasis pengalaman, produk harus mampu membangkitkan sensasi dan pengalaman yang akan menjadi dasar kesetiaan pelanggan (Schmitt, 2010). Dengan pembentukan sebuah identitas, sebuah penginapan dapat ditampilkan secara khusus dan unik. Oleh karena itu, penginapan bukan hanya sebagai sarana untuk kebutuhan tidur dan menginap tetapi juga sebagai wahana rekreasi dan tempat bersantai dengan keluarga ataupun teman.

Salah satu hotel yang berada di kota Bandung adalah Ahadiat Hotel \& Bungalow. Semakin banyaknya pesaing menjadikan pengelola sadar bahwa persaingan pada industri ini semakin ketat. Pihak pengelola usaha harus benar-benar cerdik dalam memikirkan strategi yang tepat untuk menghadapi persaingan tersebut. Semakin banyaknya pesaing membuat konsumen memiliki lebih banyak pilihan. Untuk mengatasi hal tersebut, setiap penginapan harus memiliki ciri khas yang berbeda, baik dari segi layanan, penataan interior maupun fasilitas-fasilitas yang disediakan.

Ahadiat Hotel \& Bungalow memiliki konsep yang berbeda dengan penginapan lain yang berada di Bandung. Terletak di Sukajadi yang hanya berjarak 10 kilometer dari pusat kota, Ahadiat Hotel \& Bungalow terkesan unik dan menarik karena terhindar dari keramaian tetapi berada tidak jauh dari pusat kota. Adanya konsep bungalow dengan danau buatan membuat Ahadiat Hotel \& Bungalow menawarkan suasana pesona alam Bandung yang sejuk tetapi dengan lokasi yang mudah dijangkau dari pusat kota. Di Ahadiat Hotel \& Bungalow, pelanggan bukan hanya dipuaskan oleh jasa yang ditawarkan tetapi juga pengalaman emosional (sense, feel, think, act, dan relate) yang mereka dapatkan dari awal sampai akhir.

Berdasarkan latar belakang penelitian di atas, peneliti tertarik untuk melakukan penelitian tentang "Pengaruh Dimensidimensi Pemasaran berbasis pengalaman Terhadap Kesetiaan Pelanggan dengan Menggunakan Kepuasan Sebagai Peubah 
pemediasi pada Ahadiat Hotel \& Bungalow, Bandung"

\section{Rumusan Masalah Penelitian}

Berdasarkan latar belakang penelitian diatas, maka dirumuskan persoalan penelitian sebagai berikut :

1. Apakah ada pengaruh sense marketing terhadap kepuasan pelanggan pada Ahadiat Hotel \& Bungalow, Bandung?

2. Apakah ada pengaruh feel marketing terhadap kepuasan pelanggan pada Ahadiat Hotel \& Bungalow, Bandung?

3. Apakah ada pengaruh think marketing terhadap kepuasan pelanggan pada Ahadiat Hotel \& Bungalow, Bandung?

4. Apakah ada pengaruh act marketing terhadap kepuasan pelanggan pada Ahadiat Hotel \& Bungalow, Bandung?

5. Apakah ada pengaruh relate marketing terhadap kepuasan pelanggan pada Ahadiat Hotel \& Bungalow, Bandung?

6. Apakah ada pengaruh sense marketing terhadap kesetiaan pelanggan pada Ahadiat Hotel \& Bungalow, Bandung?

7. Apakah ada pengaruh feel marketing terhadap kesetiaan pelanggan pada Ahadiat Hotel \& Bungalow, Bandung?

8. Apakah ada pengaruh think marketing terhadap kesetiaan pelanggan pada Ahadiat Hotel \& Bungalow, Bandung?

9. Apakah ada pengaruh act marketing terhadap kesetiaan pelanggan pada Ahadiat Hotel \& Bungalow, Bandung?

10. Apakah ada pengaruh relate marketing terhadap kesetiaan pelanggan pada Ahadiat Hotel \& Bungalow, Bandung?

11. Apakah ada pengaruh kepuasan pelanggan terhadap kesetiaan pelanggan pada Ahadiat Hotel \& Bungalow, Bandung?

\section{Tujuan Penelitian}

Berdasarkan rumusan masalah penelitian, ditetapkan tujuan penelitian sebagai berikut, yaitu untuk :

1. Mengetahui pengaruh sense marketing terhadap kepuasan pelanggan pada Ahadiat Hotel \& Bungalow, Bandung.
2. Mengetahui pengaruh feel marketing terhadap kepuasan pelanggan pada Ahadiat Hotel \& Bungalow, Bandung.

3. Mengetahui pengaruh think marketing terhadap kepuasan pelanggan pada Ahadiat Hotel \& Bungalow, Bandung.

4. Mengetahui pengaruh act marketing terhadap kepuasan pelanggan pada Ahadiat Hotel \& Bungalow, Bandung.

5. Mengetahui pengaruh relate marketing terhadap kepuasan pelanggan pada Ahadiat Hotel \& Bungalow, Bandung.

6. Mengetahui pengaruh sense marketing terhadap kesetiaan pelanggan pada Ahadiat Hotel \& Bungalow, Bandung.

7. Mengetahui pengaruh feel marketing terhadap kesetiaan pelanggan pada Ahadiat Hotel \& Bungalow, Bandung.

8. Mengetahui pengaruh think marketing terhadap kesetiaan pelanggan pada Ahadiat Hotel \& Bungalow, Bandung.

9. Mengetahui pengaruh act marketing terhadap kesetiaan pelanggan pada Ahadiat Hotel \& Bungalow, Bandung.

10. Mengetahui pengaruh relate marketing terhadap kesetiaan pelanggan pada Ahadiat Hotel \& Bungalow, Bandung.

11. Mengetahui pengaruh kepuasan pelanggan terhadap kesetiaan pelanggan pada Ahadiat Hotel \& Bungalow, Bandung.

\section{Manfaat Penelitian}

Manfaat yang diperoleh dari penelitian ini sebagai berikut :

1. Manfaat Teoritis

Penelitian ini dapat digunakan untuk lebih memahami teori-teori manajemen pemasaran dan perilaku konsumen, khususnya tentang Pemasaran berbasis pengalaman, kepuasan, dan kesetiaan pelanggan. Penelitian ini juga dapat digunakan sebagai pendukung penelitian-penelitian selanjutnya di bidang perhotelan dan pariwisata.

2. Manfaat Praktis

Penelitian ini dapat digunakan sebagai masukan bagi pihak-pihak pengelola Hotel dalam menentukan strategi pemasaran yang tepat untuk menghadapi 
persaingan yang semakin ketat di industri perhotelan sekarang ini.

\section{Tinjauan Pustaka \\ Kesetiaan Pelanggan}

Kesetiaan pelanggan sangat penting artinya bagi perusahaan yang ingin menjaga kelangsungan hidup maupun keberhasilan usahanya. Kesetiaan pelanggan merupakan dorongan perilaku untuk melakukan pembelian secara berulang-ulang dan membangun kesetiaan pelanggan terhadap produk yang dihasilkan (Schiffman and Wisenblit, 2015). Keuntungan-keuntungan yang akan diperoleh perusahaan apabila memiliki pelanggan yang setia antara lain (Griffin, 2005) :

1. Mengurangi biaya pemasaran (karena biaya untuk menarik pelanggan baru lebih mahal).

2. Mengurangi biaya transaksi (seperti biaya kontrak, pemrosesan pesanan, dan lainlain).

3. Mengurangi biaya perputaran pelanggan (karena pergantian pelanggan yang lebih sedikit).

4. Meningkatkan penjualan silang yang akan memperbesar pangsa pasar perusahaan.

5. Getok tular yang lebih positif dengan asumsi bahwa pelanggan yang setia juga pasti telah merasa puas.

\section{Kepuasan Pelanggan}

Kepuasan pelanggan merupakan tingkat perasaan seseorang setelah membandingkan kinerja produk (atau hasil) yang dirasakan dengan harapan konsumen (Kotler dan Keller, 2012). Kepuasan merupakan sebuah fungsi dari perbedaan antara kinerja yang dirasakan dan harapan yang didapatkan. Pelanggan dapat mengalami salah satu dari tiga tingkat kepuasan yang umum. Kepuasan atau rasa senang yang tinggi menciptakan ikatan emosional dengan merek atau perusahaan tersebut, tidak hanya sekedar kelebih-sukaan rasional. Manfaat-manfaat spesifik kepuasan pelanggan bagi perusahaan mencakup (Muthiah, 2013) :

1. Dampak positif pada kesetiaan pelanggan
2. Berpotensi menjadi sumber pendapatan masa depan (terutama melalui pembelian ulang, cross-selling dan up-selling).

3. Menekan biaya transaksi pelanggan di masa depan (terutama biaya-biaya komunikasi, penjualan dan layanan pelanggan).

4. Menekan risiko berkenaan dengan prediksi aliran kas masa depan.

5. Meningkatkan toleransi harga (terutama kesediaan untuk membayar harga premium dan pelanggan tidak mudah untuk beralih ke pesaing)

6. Rekomendasi getok tular positif.

7. Pelanggan cenderung lebih menerima terhadap produk dan layanan tambahan yang ditawarkan perusahaan.

\section{Pemasaran berbasis pengalaman}

Pemasaran berbasis pengalaman merupakan sebuah strategi pemasaran dengan melihat konsumen sebagai manusia rasional dan emosional yang menginginkan suatu pencapaian pengalaman yang menyenangkan. Pemasaran berbasis pengalaman adalah cara baru menciptakan pengalaman hidup pelanggan melalui penciptaan emosi yang berkaitan dengan enam indra, yaitu bau, penglihatan, rasa, pendengaran, sentuhan dan keseimbangan (Schmitt, 2010). Pemasaran berbasis pengalaman dianggap sebagai proses mengidentifikasi dan memuaskan kebutuhan pelanggan secara menguntungkan, dengan melibatkan pelanggan dalam komunikasi dua arah yang membawa kepribadian merek menjadi nyata dan menambah nilai bagi pelanggan. Hal tersebut menciptakan kenangan dan pengalaman yang masuk ke dalam benak pelanggan (Maghnati et al., 2012).

Pemasaran berbasis pengalaman adalah tentang bagaimana menemukan wawasan passion dari masyarakat melalui keterhubungan yang diciptakan secara alami dan unik antara mereka dan ekuitas merek (Sharma and Sharma, 2011). Pemasaran berbasis pengalaman merupakan peristiwa atau pengalaman yang memberikan sasaran untuk menjelajahi produk dan pengalaman 
untuk menciptakan pembelian di masa mendatang. Pemasaran berbasis pengalaman merupakan pemasaran produk dengan merangsang unsur-unsur emosi konsumen yang akan menghasilkan berbagai pengalaman bagi konsumen dalam mengasosiasikan identitas sosial ke dalam keterhubungan terhadap suatu kelompok acuan dan budaya. Pendekatan ini dinilai sangat efektif karena sejalan dengan perkembangan jaman dan teknologi, di mana para pemasar lebih menekankan diferensiasi produk untuk membedakan produknya dengan produk kompetitor (Adeosun, 2013).

$\begin{array}{lcc}\begin{array}{l}\text { Karakteristik } \\ \text { Pengalaman }\end{array} & \text { Pemasaran } & \text { Berbasis } \\ \text { Pendekatan } & \text { Pemasaran } & \text { berbasis }\end{array}$
pengalaman pertama kali dikemukakan oleh Bernd Schmitt pada tahun 1999. Pendekatan Pemasaran berbasis pengalaman merupakan pendekatan yang mencoba menggeser pendekatan pemasaran tradisional. Terdapat empat karakteristik dari Pemasaran berbasis pengalaman yang membedakannya dengan pemasaran tradisional yaitu (Kustini, 2007) :

1. Fokus pada pengalaman pertama

Berbeda dengan pemasaran tradisional, Pemasaran berbasis pengalaman berfokus pada pengalaman pelanggan. Pengalaman yang terjadi akibat pertemuan, menjalani atau melewati situasi tertentu. Pengalaman memberikan nilai-nilai inderawi, emosional, kognitif, perilaku dan relasional yang menggantikan nilainilai fungsional.

2. Menguji situasi konsumsi

Pemasaran berbasis pengalaman menciptakan sinergi untuk dapat meningkatkan pengalaman konsumsi. Pelanggan tidak hanya mengevaluasi suatu produk sebagai produk yang berdiri sendiri dan tidak hanya menganalisis tampilan dan fungsi saja, melainkan pelanggan lebih menginginkan suatu produk yang sesuai dengan situasi dan pengalaman pada saat mengonsumsi produk tersebut.

3. Mengenali aspek rasional dan emosional sebagai pemicu dari konsumsi
Jangan memperlakukan pelanggan hanya sebagai pembuat keputusan yang rasional, pelanggan ingin dihibur, dirangsang, dipengaruhi secara emosional dan ditantang secara kreatif.

4. Metode dan perangkat bersifat elektik Metode dan perangkat untuk mengukur pengalaman seseorang bersifat elektik, yaitu tidak hanya terbatas pada suatu metode saja, melainkan memilih metode dan perangkat yang sesuai tergantung dari obyek yang diukur. Jadi lebih bersifat pada kekhususan untuk setiap situasi daripada menggunakan suatu standar yang sama.

\section{Strategic Experiential Modules (SEMs)}

Strategic Experiential Modules (SEMs) dapat digunakan untuk menciptakan berbagai jenis pengalaman pada Pemasaran berbasis pengalaman. Kertajaya (2004) menjelaskan bahwa Pemasaran berbasis pengalaman dapat diukur dengan menggunakan lima dimensi sebagai berikut :

\section{Sense Marketing}

Sense marketing merupakan upaya pemasaran untuk menciptakan stimulus yang dapat memiliki daya tarik inderawi konsumen dengan tujuan menciptakan pengalaman personal melalui pengelihatan, suara, sentuhan, rasa dan bau.

\section{Feel Marketing}

Feel marketing merupakan upaya pemasaran dengan cara menarik perasaan dan emosi pelanggan yang lebih mendalam, bertujuan menciptakan pengalaman yang dapat menciptakan perasaan gembira dan kebanggaan yang kuat terhadap merek.

3. Think Marketing

Think marketing merupakan upaya pemasaran dengan cara menciptakan daya tarik intelektual dengan tujuan menciptakan pengalaman kognitif dan pemecahan masalah yang menarik bagi pelanggan secara kreatif.

4. Act Marketing

Act marketing merupakan upaya pemasaran yang bertujuan untuk 
memengaruhi pengalaman tubuh, gaya hidup dan interaksi dengan orang lain.

5. Relate Marketing

Relate marketing digunakan untuk mempengaruhi pelanggan dengan menggabungkan seluruh aspek sense, feel, think dan act serta menitikberatkan pada penciptaan persepsi positif di mata pelanggan. Tujuannya adalah mengaitkan individu dengan apa yang ada di luar dirinya - dalam hal hubungan antara orang lain dan kelompok sosial sehingga mereka merasa bangga dan diterima dalam komunitas.

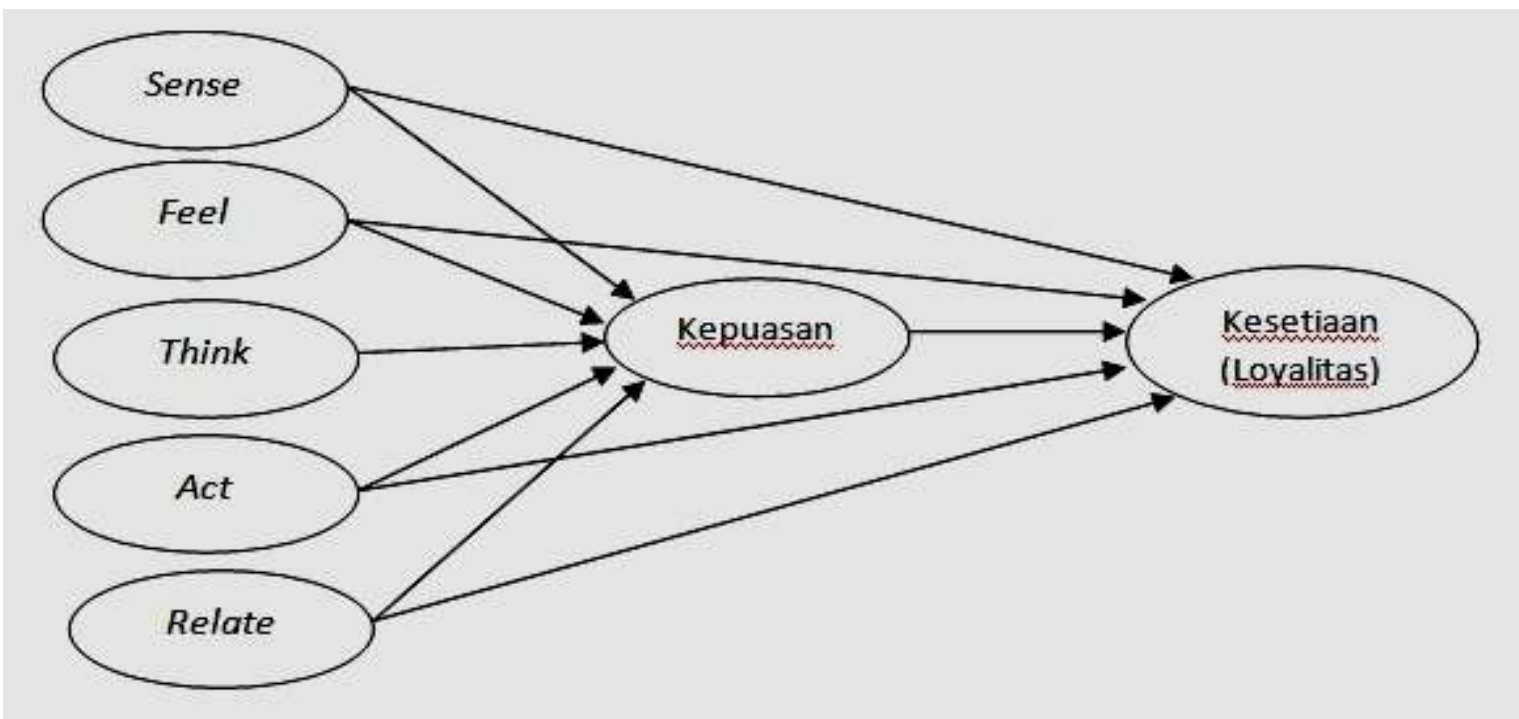

Gambar 1 - Model Penelitian

\section{Metode Penelitian \\ Metode Penelitian}

Penelitian dilakukan dengan metode kuantitatif yang menekankan analisisnya pada data numerik yang diolah dengan metode statistik. Menurut kedalamannya, penelitian ini termasuk pada penelitian inferensial yang melakukan analisis keterhubungan antar peubah dengan pengujian hipotesis. Subyek penelitian ini adalah orang yang pernah menginap di Ahadiat Hotel \& Bungalow, Bandung. Obyek penelitian ini adalah kesetiaan, kepuasan, sense, feel, think, act, dan relate.

\section{Populasi dan Sampel}

Populasi dalam penelitian ini adalah orang yang pernah menginap di Ahadiat Hotel \& Bungalow, Bandung. Teknik pengambilan sampel dilakukan dengan cara non probability sampling yaitu setiap unsur yang terdapat dalam populasi tidak memiliki kesempatan atau peluang yang sama untuk dipilih menjadi sampel, bahkan probabilitas anggota tertentu untuk terpilih tidak diketahui (Siregar, 2013). Teknik penentuan sampel dilakukan dengan convenience sampling yaitu teknik penentuan sampel berdasarkan kebetulan saja, dimana anggota populasi yang ditemui peneliti bersedia menjadi responden. Karena keterbatasan waktu penyebaran kusioner, maka sampai dengan waktu yang ditentukan hanya diperoleh 107 responden. Jumlah ini dianggap sudah cukup, didasarkan pada pendapat Roscoe (1982; Sugiyono, 2013) yang menyatakan bahwa ukuran sampel yang layak dalam penelitian adalah antara 30 sampai dengan 500.

Teknik pengumpulan data dalam penelitian melalui observasi, wawancara dan kuisioner. Pengisian kuisioner dilakukan oleh pewawancara berdasarkan jawaban dari responden. Pengisian kusioner oleh pewawancara dilakukan untuk menghindari bias dalam penjawab pertanyaan, karena kemungkinan responden telah melihat seluruh isi pertanyaan dalam kusioner. 
Peubah-peubah Penelitian

Kesetiaan Pelanggan (Z) adalah sikap seseorang pada produk atau jasa tertentu. Peubah ini diukur dengan menggunakan skala Likert 5 skala dari 1 s/d 5, di mana angka 1 sangat tidak setuju dan angka 5 sangat setuju.

Kepuasan Pelanggan ( $\mathrm{Y}$ ) adalah tingkat perasaan seseorang setelah membandingkan kinerja produk (atau hasil) yang dirasakan dengan harapannya. Peubah ini diukur dengan menggunakan skala Likert 5 skala dari 1 s/d 5, di mana angka 1 sangat tidak setuju dan angka 5 sangat setuju.

Sense Marketing (X1) adalah upaya pemasaran untuk menciptakan pengalaman pribadi melalui daya tarik inderawi konsumen. Peubah ini diukur dengan menggunakan skala Likert 5 skala dari $1 \mathrm{~s} / \mathrm{d}$ 5, di mana angka 1 sangat tidak setuju dan angka 5 sangat setuju.

Feel Marketing (X2) adalah upaya pemasaran untuk menciptakan pengalaman pribadi melalui daya tarik emosional konsumen. Peubah ini diukur dengan menggunakan skala Likert 5 skala dari $1 \mathrm{~s} / \mathrm{d}$ 5, di mana angka 1 sangat tidak setuju dan angka 5 sangat setuju.

Think Marketing (X3) adalah upaya pemasaran untuk menciptakan pengalaman pribadi melalui daya tarik kognitif konsumen. Peubah ini diukur dengan menggunakan skala Likert 5 skala dari $1 \mathrm{~s} / \mathrm{d}$ 5, di mana angka 1 sangat tidak setuju dan angka 5 sangat setuju.

Act Marketing (X4) adalah upaya pemasaran untuk menciptakan pengalaman pribadi melalui perilaku, gaya hidup, dan interaksi konsumen dengan konsumen lainnya. Peubah ini diukur dengan menggunakan skala Likert 5 skala dari $1 \mathrm{~s} / \mathrm{d}$ 5, di mana angka 1 sangat tidak setuju dan angka 5 sangat setuju.

Relate Marketing (X5) adalah upaya pemasaran untuk menciptakan pengalaman pribadi melalui daya tarik hubungan dengan orang lain dan kelompok sosial, sehingga mereka konsumen merasa bangga daan diterima dalam komunitas. Peubah ini diukur dengan menggunakan skala Likert 5 skala dari $1 \mathrm{~s} / \mathrm{d}$ 5, di mana angka 1 sangat tidak setuju dan angka 5 sangat setuju.

\section{Teknik Analisis Data}

Tahapan teknik analisis data dalam penelitian ini dilakukan sebagai berikut :

1. Pengujian Kesahihan

Pengujian kesahihan dalam penelitian ini menggunakan uji kesahihan konvergen dan kesahihan diskriminan. Kesahihan konvergen digunakan berhubungan dengan prinsip bahwa indikator-indikator (manifest variabel) dari suatu konstruk seharusnya berkorelasi tinggi. Kesahihan konvergen dilihat dari hasil loading faktor untuk setiap indikator dari konstruk dengan nilai loading factor> 0,7, Selain dari loading factor, pengukuran kesahihan konvergen dilakukan dengan nilai Average Variance Extracted (AVE) harus > 0,5 yang mempunyai arti bahwa 50\% atau lebih varian dari indikator dapat dijelaskan (Latan dan Ghozali, 2012). Selanjutnya, kesahihan diskriminan berhubungan dengan prinsip indikator-indikator dari konstruk yang berbeda seharusnya tidak berkorelasi tinggi. Cara untuk menguji kesahihan diskriminan dengan indikator refleksi yaitu dengan melihat cross loading setiap peubah harus $>0,7$.

2. Pengujian Keandalan

Pengujian terhadap tingkat keandalan dimaksudkan untuk mengetahui apakah kuesioner dapat memberikan ukuran yang konstan atau tidak. Instrumen (kuesioner) yang handal mampu mengungkapkan data yang dapat dipercaya. Untuk mengukur keandalan, dapat dilakukan dengan uji koefisien Alpha Cronbach dan kehandalan komposit (Composite Reliability). Koefisien Alpha Cronbach dan kehandalan komposit harus berada di atas 0,70 untuk menunjukkan konsistensi keandalan yang memuaskan (Latan dan Ghozali, 2012).

3. Analisis Koefisien Korelasi

Analisis korelasi adalah suatu teknik statistik yang digunakan untuk mengukur keeratan hubungan atau korelasi antara 
dua peubah (Suharyadi dan Purwanto, 2013). Koefisien korelasi mempunyai nilai antara -1 sampai 1 . Nilai $r=-1$ yang disebut dengan linier sempurna negatif, terjadi apabila contoh atau kombinasi terletak tepat pada suatu garis lurus yang mempunyai kemiringan negatif. Nilai $r=$ 1 disebut dengan linier sempurna positif, dan hal ini terjadi apabila semua titik contoh terletak tepat pada satu garis lurus dengan kemiringan positif. Nilai koefisien korelasi yang mendekati -1 atau 1 menyatakan bahwa hubungan kedua peubah adalah kuat atau korelasi kedua peubah tinggi. Akan tetapi apabila nilai $r$ mendekati 0, hubungan antara kedua peubah sangat lemah atau mungkin tidak ada sama sekali.

4. Partial Least Squares (PLS)

Partial least square atau disingkat PLS merupakan jenis SEM yang berbasis komponen dengan sifat konstruk formatif. PLS pertama kali dikembangkan oleh HermanWold akhir 1960an untuk mengolah data di bidang econometrics sebagai alternative SEM dengan dasar teori yang lemah, dan berfungsi hanya sebagai alat analisis predictor bukan uji model (Mustafa dan Wijaya, 2012).

PLS juga dapat disebut sebagai teknik prediction-oriented. Pendekatan PLS secara khusus berguna juga untuk memprediksi peubah gayut dengan melibatkan sejumlah besar peubah bebas. PLS dapat juga digunakan dalam meprediksi dalam model sehingga PLS sering diaplikasikan tidak semata dalam analisis konfirmatori tetapi juga dalam studi eksploratori ketika dasar teorinya masih lemah. Pendekatan PLS adalah distribution free (tidak mengasumsikan data berdistribusi tertentu, dapat berupa nominal, kategori, ordinal, interval dan rasio). PLS awalnya diberi nama NIPALS (Nonlinear Iterative Partial Least Square).

Dengan pendekatan PLS diasumsikan bahwa semua ukuran variance adalah variance yang berguna untuk dijelaskan.
Oleh karena pendekatan untuk mengestimasi peubah laten dianggap sebagai kombinasi linear dari indikator, maka mampu menghindarikan masalah indeterminacy dan memberikan definisi yang pasti dari komponen skor (Mustafa dan Wijaya, 2012). Dalam PLS arah keterhubungan kausalitas dari indikator ke konstruk atau membentuk konstruk. Sesama indikator diasumsikan tidak berkorelasi sehingga tidak perlu diuji konsistensi/keandalan internal. Hilangnya salah satu indikator dapat mengakibatkan perubahan makna dari konstruk.

Analisis dengan PLS menerapkan dua tahap penting yaitu model pengukuran (the measurement model) dan model struktural (structural model). Data model pengukurang dievaluasi untuk menentukan kesahihan dan keandalan. Bagian dari tahap model pengukuran meliputi :

a. Individul loading dari setiap butir pertanyaan.

b. Internal composite reliability (ICR)

c. Average variance extracted (AVE)

d. Discriminant validity

Apabila data telah memenuhi syarat dalam model pengukuran, tahap selanjutnya adalah mengevaluasi model struktural. Model struktural menguji hipotesis yang hasilnya ditunjukkan melalui signifikansi dari :
a. Path coefficients (standardized beta)
b. t-statistic
c. r-squared value

\section{Hasil Penelitian dan Pembahasan Profil Ahadiat Hotel \& Bungalow}

Ahadiat Hotel \& Bungalow terletak di jalan Sindang Sirna Elok (Prof.Sutami) No. 9 Setrasari, Sukajadi, Bandung, Indonesia 40163. Ahadiat Hotel \& Bungalow terletak hanya sekitar 10 kilometer dari pusat kota dan untuk menuju bandara dapat ditempuh dalam waktu 15 menit. Hotel ini juga memiliki akses yang mudah ke sejumlah 
obyek wisata, seperti Museum Barli, Karang Setra Waterland, Paris Van Java Mall. Hotel memiliki 59 kamar yang terdiri dari Superior Twin Bed, Deluxe Twin Bed, Executive Balcony, 1 Bedroom Bungalow, dan 3 Bedroom Bungalow.

Fasilitas yang dapat diperoleh di Ahadiat Hotel \& Bungalow, antara lain : antar-jemput bandara, adanya area merokok, business center, check-in/check-out pribadi, coffee shop, concierge, dry cleaning, fasilitas BBQ, fasilitas pertemuan, dan lain-lain. Kegiatan olahraga dan rekreasi yang ada di Ahadiat Hotel \& Bungalow, antara lain : karaoke, klub anak-anak, kolam renang (luar ruangan), kolam renang anak, lapangan golf (berjarak 3 $\mathrm{km})$, memancing, menunggang kuda, pijat, taman bermain anak, tenis meja, dan lainlain.

\section{Deskripsi Responden Penelitian}

Responden dalam penelitian ini adalah orang yang pernah menginap di Ahadiat Hotel \& Bungalow, Bandung. Dari 107 data kuesioner yang telah berhasil dikumpulkan dapat dijabarkan beberapa profil responden sebagai berikut :

Tabel 1 - Profil Responden - Jender

\begin{tabular}{|c|c|c|c|}
\hline \multirow{2}{*}{ Responden } & \multirow{2}{*}{ Keterangan } & \multicolumn{2}{|c|}{ Frekuensi } \\
\cline { 3 - 4 } & & Jumlah & Persentase \\
\hline \multirow{2}{*}{ Jender } & Laki-laki & 52 & 48,6 \\
\cline { 2 - 4 } & Perempuan & 55 & 51,4 \\
\hline
\end{tabular}

Sumber : Data primer $(\mathrm{n}=107)$

Terdapat 52 responden yang berjender perempuan. Mayoritas responden berjender laki-laki dan 55 responden yang adalah berjender perempuan sebanyak $51,4 \%$

Tabel 2 - Profil Responden - Usia

\begin{tabular}{|c|c|c|c|}
\hline \multirow{2}{*}{ Responden } & \multirow{2}{*}{ Keterangan } & \multicolumn{2}{|c|}{ Frekuensi } \\
\cline { 3 - 4 } & & Jumlah & Persentase \\
\hline \multirow{3}{*}{ Usia } & $<20$ tahun & 1 & 0,93 \\
\cline { 2 - 4 } & $21-40$ tahun & 84 & 78,51 \\
\cline { 2 - 4 } & $41-60$ tahun & 21 & 19,63 \\
\cline { 2 - 4 } & $>60$ tahun & 1 & 0,93 \\
\hline
\end{tabular}

Sumber : Data primer $(\mathrm{n}=107)$

Terdapat 1 responden yang berusia $<20 \quad 41-60$ tahun, dan 1 responden yang berusia tahun, 84 responden yang berusia antara $21->60$ tahun. Mayoritas responden adalah 40 tahun, 21 responden yang berusia antara berusia $21-40$ tahun sebesar 78,51\%. 
Tabel 3 - Profil Responden - Pekerjaan

\begin{tabular}{|c|c|c|c|}
\hline \multirow{2}{*}{ Responden } & \multirow{2}{*}{ Keterangan } & \multicolumn{2}{|c|}{ Frekuensi } \\
\cline { 3 - 4 } & & Jumlah & Persentase \\
\hline \multirow{4}{*}{ Pekerjaan } & Ibu RT & 26 & 24,3 \\
\cline { 2 - 4 } & Karyawan & 43 & 40,2 \\
\cline { 2 - 4 } & Mahasiswa & 2 & 1,9 \\
\cline { 2 - 4 } & Wiraswasta & 36 & 33,6 \\
\hline
\end{tabular}

Sumber : Data primer $(\mathrm{n}=107)$

Terdapat 26 responden adalah ibu rumah responden adalah wiraswasta. Mayoritas tangga, 43 responden adalah karyawan, 2 responden adalah karyawan sebesar 40,2\%. responden adalah mahasiswa, dan 36

Tabel 4 - Profil Responden - Penghasilan per bulan

\begin{tabular}{|c|c|c|c|}
\hline \multirow{2}{*}{ Responden } & \multirow{2}{*}{ Keterangan } & \multicolumn{2}{|c|}{ Frekuensi } \\
\cline { 3 - 4 } & & Jumlah & Persentase \\
\hline \multirow{3}{*}{$\begin{array}{c}\text { Penghasilan/ } \\
\text { bulan }\end{array}$} & $\leq 10$ juta & 39 & 36,45 \\
\cline { 2 - 4 } & $11-20$ juta & 37 & 34,58 \\
\cline { 2 - 4 } & $21-30$ juta & 20 & 18,69 \\
\cline { 2 - 4 } & $31-40$ juta & 11 & 10,28 \\
\hline
\end{tabular}

Sumber : Data primer $(\mathrm{n}=107)$

Terdapat 39 responden yang memiliki penghasilan $\leq 10$ juta rupiah per bulan, 37 responden yang memiliki penghasilan 11 20 juta rupiah per bulan, 20 responden yang memiliki penghasilan $21-30$ juta rupiah per bulan, dan 11 responden yang memiliki penghasilan $31-40$ juta rupiah per bulan. Mayoritas responden adalah yang berpenghasilan $\leq 10$ juta per bulan sebesar $36,45 \%$. 
Model PLS-algorithm dalam penelitian ini sebagai berikut:

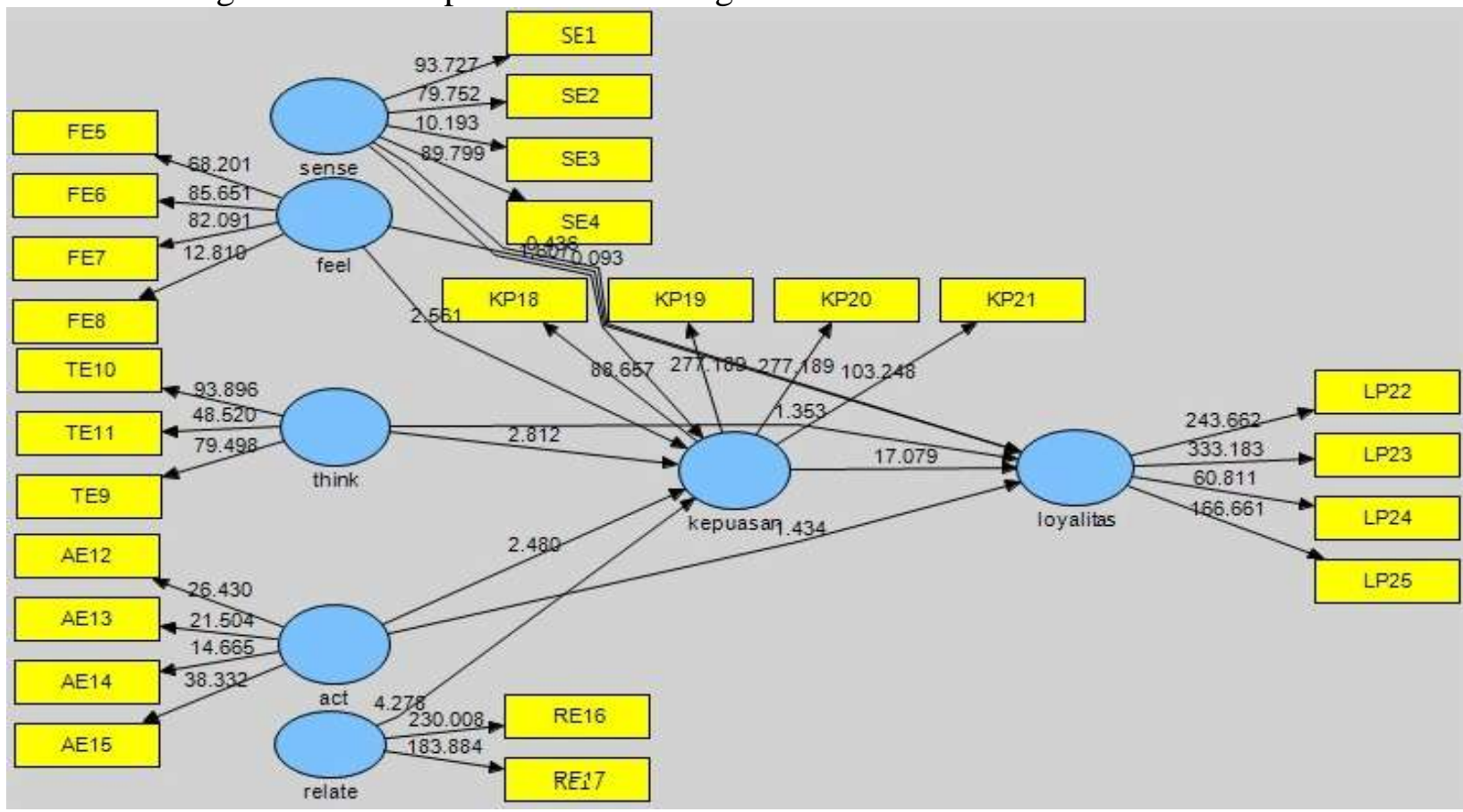

Gambar 2 - Model PLS-ALGORITHM

Sumber: Data primer $(\mathrm{n}=107)$

Uji Kesahihan dan Kehandalan

Tabel 5 - Uji Kesahihan Konvergen Outer Loadings

\begin{tabular}{|c|c|c|c|c|c|c|c|}
\hline & SE & FE & TE & $\mathbf{A E}$ & RE & KP & LP \\
\hline SE1 & 0.963415 & & & & & & \\
\hline SE2 & 0,958322 & & & & & & \\
\hline SE3 & 0.644485 & & & & & & \\
\hline SE4 & 0.954074 & & & & & & \\
\hline FE5 & & 0.963484 & & & & & \\
\hline FE6 & & 0.964067 & & & & & \\
\hline FE7 & & 0.961944 & & & & & \\
\hline FE8 & & 0.741984 & & & & & \\
\hline TE9 & & & 0.948006 & & & & \\
\hline TE10 & & & 0.888933 & & & & \\
\hline TE11 & & & 0.947864 & & & & \\
\hline AE12 & & & & 0.886164 & & & \\
\hline AE13 & & & & 0.865905 & & & \\
\hline AE14 & & & & 0.713851 & & & \\
\hline AE15 & & & & 0.887697 & & & \\
\hline RE16 & & & & & 0.983720 & & \\
\hline RE17 & & & & & 0.980925 & & \\
\hline KP18 & & & & & & 0.959456 & \\
\hline KP19 & & & & & & 0.985769 & \\
\hline KP20 & & & & & & 0.985769 & \\
\hline KP21 & & & & & & 0.967557 & \\
\hline LP22 & & & & & & & 0.986232 \\
\hline LP23 & & & & & & & 0.988578 \\
\hline LP24 & & & & & & & 0.947048 \\
\hline LP25 & & & & & & & 0.979526 \\
\hline
\end{tabular}

Sumber : Data primer $(\mathrm{n}=107)$

Berdasarkan hasil dari uji kesahihan mengelompok sesuai dengan indikator konvergen, semua peubah dinyatakan sahih masing-masing.

karena memiliki nilai $>0,50$ dan 
Tabel 6 - Average Variance Extracted (AVE) AVE

\begin{tabular}{|c|c|}
\hline & AVE \\
\hline act & 0.708167 \\
\hline feel & 0.833400 \\
\hline kepuasan & 0.950051 \\
\hline loyalitas & 0.951578 \\
\hline relate & 0.964959 \\
\hline sense & 0.793042 \\
\hline think & 0.862455 \\
\hline
\end{tabular}

Sumber : Data primer $(\mathrm{n}=107)$

Berdasarkan hasil analisis dengan dinyatakan sahih karena memiliki nilai > menggunakan uji AVE, semua peubah 0,50.

Tabel 7 - Koefisien Alpha Cronbach

\section{Cronbachs Alpha}

\begin{tabular}{|c|c|}
\hline & Cronbachs Alpha \\
\hline act & 0.859204 \\
\hline feel & 0.928969 \\
\hline kepuasan & 0.982427 \\
\hline loyalitas & 0.982946 \\
\hline relate & 0.963743 \\
\hline sense & 0.903735 \\
\hline think & 0.919818 \\
\hline
\end{tabular}

Sumber : Data primer $(\mathrm{n}=107)$

Berdasarkan hasil analisis yang karena memiliki nilai koefisien Apha dilakukan, semua peubah dinyatakan handal Cronbach $>0,60$.

Tabel 8 - Kehandalan Komposit Composite Reliability

\begin{tabular}{|c|c|}
\hline & $\begin{array}{c}\text { Composite } \\
\text { Reliability }\end{array}$ \\
\hline act & 0.905967 \\
\hline feel & 0.951899 \\
\hline kepuasan & 0.987025 \\
\hline loyalitas & 0.987435 \\
\hline relate & 0.982167 \\
\hline sense & 0.937382 \\
\hline think & 0.949480 \\
\hline
\end{tabular}

Sumber : Data primer $(\mathrm{n}=107)$

Berdasarkan hasil analisis yang dinyatakan handal karena memiliki nilai > dilakukan dengan menggunakan uji 0,70 .

kehandalan komposit semua peubah 
Kecocokan Model Struktural

Untuk mendapatkan output SmartPLS maka dibutuhkan koefisien determinasi, koefisien T-Statistik, koefisien parameter, dan koefisien korelasi.

Tabel 9 - R Square

\section{R Square}

\begin{tabular}{|c|c|}
\hline & R Square \\
\hline act & \\
\hline feel & \\
\hline kepuasan & 0.810890 \\
\hline loyalitas & 0.906517 \\
\hline relate & \\
\hline sense & \\
\hline think & \\
\hline
\end{tabular}

Sumber : Data primer $(\mathrm{n}=107)$

Berdasarkan hasil uji koefisien yang dilakukan dengan menggunakan uji koefisien determinasi menunjukkan bahwa:

1) Dimensi-dimensi sense, feel, think, act, dan relate dapat menjelaskan perubahan kepuasan pelanggan sebesar 0,810890 atau $81.09 \%$.
2) Kepuasan pelanggan menyebabkan perubahan kesetiaan pelanggan sebesar 0,906517 atau 90,65\%.

Tabel 10 - Uji T

\begin{tabular}{|c|c|}
\hline & $\begin{array}{l}\text { T Statistics } \\
\text { (IO/STERRI) }\end{array}$ \\
\hline act $\rightarrow$ kepuasan & 2.457912 \\
\hline act-> lovalitas & 1.476102 \\
\hline feel $\rightarrow$ kepuasan & 2.365493 \\
\hline feel $\rightarrow$ loyalitas & 1.983197 \\
\hline $\begin{array}{c}\text { kepuasan } \rightarrow \\
\text { loyalitas }\end{array}$ & 17.736947 \\
\hline $\begin{array}{l}\text { relate }-> \\
\text { kepuasan }\end{array}$ & 3.918976 \\
\hline $\begin{array}{l}\text { relate } \rightarrow \\
\text { lovalitas }\end{array}$ & 4.014086 \\
\hline $\begin{array}{l}\text { sense }-> \\
\text { kepuasan }\end{array}$ & 1.533295 \\
\hline sense $->$ loyalitas & 1.621334 \\
\hline $\begin{array}{l}\text { think } \rightarrow \\
\text { kepuasan }\end{array}$ & 3.106106 \\
\hline think $\rightarrow$ loyalitas & 3.313608 \\
\hline
\end{tabular}

Sumber : Data primer $(\mathrm{n}=107)$

Berdasarkan hasil uji t yang dilakukan dengan menggunakan program SmartPLS 2, menunjukkan berikut ini:

\section{Hipotesis 1}

Pada hipotesis 1 telah didapatkan hasil $1,53<1,96$ (t-hitung < t-tabel) maka $\mathrm{HO}_{1}$ diterima dan $\mathrm{Ha}_{1}$ ditolak, berarti tidak terdapat pengaruh yang signifikan antara sense marketing terhadap kepuasan pelanggan. Dimensi sense marketing merujuk pada pengalaman yang ditawarkan kepada responden berkaitan dengan indera penglihatan, indera perasa, indera penciuman, dan indera pendengaran. Temuan penelitian mengindikasikan bahwa selama berada di Ahadiat Hotel \& Bungalow, responden memperoleh pengalaman yang mengesankan berkaitan dengan indera penglihatan (pepohonan dengan hijaunya 
dedaunan, lay-out yang tertata dengan baik, dan desain taman yang bagus). Responden merasa nyaman dengan kesejukan suasana danau buatan (rindangnya pepohonan, dan air danau yang bersih). Tetapi responden merasa bahwa lingkungan yang luas tersebut kurang terjaga kebersihannya sehingga suasana agak terganggu oleh bebauan yang kurang sedap. Penginapan yang berbentuk bungalow membuat pengelola hotel kesulitan untuk menjaga kebersihan kamarnya secara maksimal, hal ini yang mengakibatkan sebagian besar kamar bungalow kurang terjaga kebersihannya.

\section{Hipotesis 2}

Pada hipotesis 2 telah didapatkan hasil 2,36>1,96 (t-hitung > t-tabel) maka $\mathrm{HO}_{2}$ ditolak dan $\mathrm{Ha}_{2}$ diterima, berarti terdapat pengaruh yang signifikan antara feel marketing terhadap kepuasan pelanggan. Dimensi feel merujuk pada pengalaman rasa aman, pelayanan yang baik, dan ketepatan waktu pelayanan. Temuan penelitian mengindikasikan bahwa pada saat menginap di Ahadiat Hotel \& Bungalow, responden merasa aman karena tempat parkir kendaraan yang memiliki akses langsung dari kamar hotel. Selama berada dalam hotel, responden merasa dilayani dengan baik oleh para petugas (mulai saat kendaraan masuk, pendaftaran, sampai dengan berada di kamar hotel). Responden merasa bahwa pelayanan yang diberikan oleh petugas hotel telah sesuai dari sisi durasi dan ketepatan waktu (proses check-in dan check-out yang mudah dan cepat). Dilihat dari dimensi feel, responden memperoleh pengalaman nyata yang sangat mengesankan berkaitan dengan rasa aman, pelayanan yang baik, dan ketepatan waktu pelayanan sehingga mampu membangkitkan emosi dan perasaan positif terhadap Ahadiat Hotel \& Bungalow.

\section{Hipotesis 3}

Pada hipotesis 3 telah didapatkan hasil 3,11 > 1,96 (t-hitung > t-tabel) maka $\mathrm{HO}_{3}$ ditolak dan $\mathrm{Ha}_{3}$ diterima, berarti terdapat pengaruh yang signifikan antara think marketing terhadap kepuasan pelanggan. Dimensi think marketing merujuk pada pengalaman yang dirasakan atas bagaimana responden memperoleh informasi kelengkapan dan ketercukupan fasilitas yang disediakan, dan letaknya yang strategis. Letak hotel yang strategis yaitu hanya berjarak 10 kilometer dari pusat kota tetapi terkesan unik dan menarik karena terhindar dari keramaian tetapi berada tidak jauh dari pusat kota, menjadi pertimbangan utama responden dalam membangkitkan pengalaman emosi yang positif terhadap Ahadiat Hotel \& Bungalow, Bandung.

\section{Hipotesis 4}

Pada hipotesis 4 telah didapatkan hasil 2,46>1,96 (t-hitung > t-tabel) maka $\mathrm{HO}_{4}$ ditolak dan $\mathrm{Ha}_{4}$ diterima, berarti terdapat pengaruh yang signifikan antara act marketing terhadap kepuasan pelanggan. Dimensi act marketing merujuk pada pengalaman yang ditawarkan kepada responden berkaitan dengan terpenuhinya keinginan yang bersifat pribadi seperti gaya hidup, daya tanggap karyawan, dan interaksi yang baik antara karyawan dan responden. Temuan ini mengindikasikan bahwa pengalaman yang ditawarkan kepada responden berkaitan dengan terpenuhinya keinginan yang bersifat pribadi seperti gaya hidup, daya tanggap karyawan, serta interaksi yang baik antara karyawan dan responden. Adanya konsep hotel seperti Ahadiat Hotel \& Bungalow ini dianggap responden telah sesuai dengan gaya hidup yang ada yaitu mencari lokasi yang menawarkan suasana pedesaan (dusun) tetapi tidak berada jauh dari pusat kota untuk memperlancar mobilitas mereka. Hal tersebut membangkitkan pengalaman emosi yang positif terhadap Ahadiat Hotel \& Bungalow, Bandung.

\section{Hipotesis 5}

Pada hipotesis 5 telah didapatkan hasil 3,92>1,96 (t-hitung > t-tabel) maka $\mathrm{HO}_{5}$ ditolak dan $\mathrm{Ha}_{5}$ diterima, berarti terdapat pengaruh yang signifikan antara relate marketing terhadap kepuasan pelanggan. Dimensi relate merujuk pada pengalaman yang ditawarkan kepada responden berkaitan dengan terciptanya komunikasi langsung 
yang baik dan pelayanan yang istimewa. Temuan penelitian menunjukkan bahwa keramahan dan pelayanan istimewa khas orang Sunda menjadi pengalaman istimewa yang dapat membangkitkan emosi positif responden terhadap Ahadiat Hotel \& Bungalow.

\section{Hipotesis 6}

Pada hipotesis 6 telah didapatkan hasil $1,62<1,96$ (t-hitung < t-tabel) maka $\mathrm{HO}_{6}$ diterima dan $\mathrm{Ha}_{6}$ ditolak, berarti tidak terdapat pengaruh yang signifikan antara sense marketing terhadap kesetiaan pelanggan. Sebagian besar pelanggan menganggap bahwa lingkungan hotel kurang terjaga kebersihannya. Kamar mandi agak bau dan sering muncul semut-semut hitam. Sarapan yang disediakan berbentuk buffet tetapi disajikan dalam keadaan dingin dan rasanya yang kurang enak. Hal ini mengakibatkan sense marketing pada Ahadiat Hotel \& Bungalow belum dapat menciptakan kesetiaan pelanggannya.

\section{Hipotesis 7}

Pada hipotesis 7 telah didapatkan hasil $1,98>1,96$ (t-hitung > t-tabel) maka $\mathrm{HO}_{7}$ diterima dan $\mathrm{Ha}_{7}$ ditolak, berarti terdapat pengaruh yang signifikan antara feel marketing terhadap kesetiaan pelanggan. Sebagian besar responden menganggap parkir kendaraan yang berada langsung di sebelah kamar (tipe Bungalow) dan proses check in dan check out yang ringkas menyebabkan mereka setia kepada Ahadiat Hotel \& Bungalow, Bandung.

\section{Hipotesis 8}

Pada hipotesis 8 telah didapatkan hasil $3,31>1,96$ (t-hitung > t-tabel) maka $\mathrm{H}_{8}$ ditolak dan $\mathrm{Ha}_{8}$ diterima, berarti terdapat pengaruh yang signifikan antara think marketing terhadap kesetiaan pelanggan. Sebagian besar responden beranggapan bahwa Ahadiat Hotel \& Bungalow terletak di kota namun terasa tinggal di Lembang karena suasananya. Lokasi dekat dengan tol juga menjadi pertimbangan responden untuk setia menginap di hotel ini.

\section{Hipotesis 9}

Pada hipotesis 9 telah didapatkan hasil 1,47 < 1,96 (t-hitung < t-tabel) maka $\mathrm{H}_{9}$ diterima dan $\mathrm{Ha}_{9}$ ditolak, berarti tidak terdapat pengaruh yang signifikan antara act marketing terhadap kesetiaan pelanggan. Daya tarik Ahadiat Hotel \& Bungalow adalah lokasi yang menawarkan suasana pedesaan (dusun) tetapi tidak berada jauh dari pusat kota untuk memperlancar mobilitas mereka. Tetapi hal ini dirasa belum cukup untuk menciptakan kesetiaan pelanggan. Hotel ini tidak direkomendasikan untuk penginap yang tidak memiliki sarana transportasi pribadi. Keberadaan sarana transportasi di Hotel ini sangat kurang sehingga membutuhkan banyak usaha untuk memperoleh sarana transportasi yang diinginkan.

\section{Hipotesis 10}

Pada hipotesis 10 telah didapatkan hasil 4,01 > 1,96 (t-hitung > t-tabel) maka $\mathrm{H}_{10}$ ditolak dan $\mathrm{Ha}_{10}$ diterima, berarti terdapat pengaruh yang signifikan antara relate marketing terhadap kesetiaan pelanggan. Sebagian besar responden menganggap bahwa staf ramah dan memberikan pelayanan yang istimewa kepada pelanggannya. Beberapa responden menyatakan bahwa ketika mereka menunggu anak-anak yang sedang berenang, tiba-tiba pihak hotel menyediakan teh hangat tanpa biaya. Staf juga mempersilahkan responden untuk sarapan di pinggir kolam renang dan membantu pelanggan menjaga anak mereka yang sedang berenang ketika orangtuanya sedang sarapan. Berdasarkan pengalaman sebelumnya ketika ada barang yang tertinggal, pihak hotel langsung menghubungi pelanggan dan mengirimkan barang yang tertinggal tersebut via ekspedisi tanpa mengenakan biaya apapun. Pelayanan yang istimewa ini membuat responden setia kepada Ahadiat Hotel \& Bungalow, Bandung.

Hipotesis 11

Pada hipotesis 11 telah didapatkan hasil 17,74 >1,96 (t-hitung > t-tabel) maka $\mathrm{HO}_{11}$ ditolak dan $\mathrm{Ha}_{11}$ diterima, berarti terdapat pengaruh yang signifikan antara kepuasan pelanggan terhadap kesetiaan pelanggan. Hal 
ini sesuai dengan pendapat Solomon (2011) yang menyatakan bahwa ketika pelanggan merasa puas terhadap produk maupun jasa yang diberikan oleh suatu perusahaan maka pelanggan akan cenderung untuk kembali melakukan pembelian ulang terhadap produk maupun mengunjungi jasa. Hal ini merupakan salah satu indikator dari timbulnya kesetiaan pelanggan.

\section{Kesimpulan dan Saran Kesimpulan}

Berdasarkan hasil penelitian dan pembahasan di atas, maka sebagai kesimpulan penelitian ini dapat dikemukakan sebagai berikut :

Hasil penelitian menunjukkan bahwa secara keseluruhan kesetiaan pelanggan dipengaruhi oleh konsep unik yang ditawarkan oleh Ahadiat Hotel \& Bungalow, Bandung. Hotel yang terletak di Sukajadi dan hanya berjarak 10 kilometer dari pusat kota ini terkesan menarik karena terhindar dari keramaian tetapi berada tidak jauh dari pusat kota. Konsep bungalow dengan danau buatan membuat pelanggan serasa berada di Lembang (daerah pegunungan di Bandung) sehingga mereka merasa tenang dan nyaman. Di Ahadiat Hotel \& Bungalow, pelanggan bukan hanya dipuaskan oleh pelayanan yang istimewa tetapi juga pengalaman emosional yang mereka dapatkan dari awal sampai akhir sehingga konsumen merasa puas. Tetapi konsep pedesaan yang luas tersebut membuat kebersihan dari Hotel kurang terjaga sehingga mengganggu pengalaman emosional pelanggan Ahadiat Hotel \& Bungalow, Bandung.

\section{Saran}

Berdasarkan kesimpulan penelitian di atas, maka saran dalam penelitian ini dapat dikemukakan sebagai berikut :

1. Ahadiat Hotel \& Bungalow, Bandung diharapkan dapat mempertahankan konsepnya yaitu menyentuh nilai emosional konsumen sehingga membentuk pengalaman tak terlupakan (memorable experience) antara pengelola dan konsumen. Pengelola dapat menambahkan fasilitas-fasilitas baru yang bertema alam sehingga memberikan pengalaman kepada pelanggan seperti berada di pedesaan Bandung. Fasilitas yang dapat ditambahkan misalnya membuat saung untuk sarapan bersama, memberikan beberapa angsa di danau buatan, mengadakan live music lagu-lagu Sunda secara reguler, atau menambah jumlah burung agar ada suasana suara burung yang dapat membuat suasana lebih nyaman.

2. Ahadiat Hotel \& Bungalow, Bandung diharapkan dapat mempertahankan bahkan meningkatkan kepuasan pelanggannya Hal ini berpengaruh sangat baik bagi pengelola karena pelanggan yang puas biasanya menceritakan pengalamannya menginap di Ahadiat Hotel \& Bungalow kepada orang lain. Hal ini dapat digunakan sebagai sarana promosi gratis bagi pihak pengelola usaha.

3. Penelitian selanjutnya diharapkan dapat meneliti tentang jasa dengan karakteristik yang berbeda, misalnya pemasaran berbasis pengalaman pada beragam gerai daring (online shop) yang ada di Indonesia (jasa yang bersifat digital). Pemasaran tradisional masih menganggap bahwa pengambilan keputusan oleh konsumen hanya melibatkan elemen rasionalitas dan logika, tanpa melibatkan aspek emosional dan irasional dalam pembelian. Pemasaran berbasis pengalaman merupakan konsep baru yang penting yang mengkombinasikan antara aspek rasionalitas dan logika dengan aspek emosional dan irasional. Dalam era informasi, teknologi, perubahan dan pilihan, setiap perusahaan perlu lebih selaras dengan para pelanggan dan pengalaman yang diberikan produk atau jasa mereka. 


\section{Daftar Pustaka}

Adeosun, L.P.K. and Ganiyu, R.A. 2013. Pemasaran Berbasis Pengalaman : An Insight into the Mind of the Consumer, Asian Journal of Business and Management Sciences, Vol.2 No.7, pp. 21-26.

Ghozali, I, dan Latan, H. 2012. Partial Least Squares: Konsep, Teknik dan Aplikasi SmartPLS 2.0 M3. Badan Penerbit Universitas Diponegoro. Semarang.

Griffin, J. 2005. Customer Loyalty : Menumbuhkan dan Mempertahankan Kesetiaan Pelanggan. Erlangga. Jakarta.

Kertajaya, H. 2005. Marketing in Venus. Mark Plus \& Co. Jakarta.

Kustini 2007. Penetapan Pemasaran Berbasis Pengalaman. Erlangga. Jakarta.

Maghnati, F., Ling, K.C., Nasermodaeli, A 2012. Exploring the Relationship between Pemasaran Berbasis Pengalaman and Experiential Value in the Smartphone Industry, International Business Research, Vol.5 No.11, pp. 167-177.

Mustafa, Z., dan Wijaya, T. 2012. Panduan Statistik SEM \& PLS dengan SPSS AMOS. Cahaya Atma Pustaka. Yogyakarta.

Muthiah, Krishnaveni. 2013. Pemasaran Berbasis Pengalaman - A Designer of Pleasurable and Memorable Experiences, Journal of Business Management \& Social Sciences Research, Vol.2 No.3, pp. 28-34.

Schiffman, L.G. and Wisenbilt, J.L. 2015. Consumer Behavior, Eleventh Edition. Pearson Education Limited. England.
Schmitt, B. 2010. Experience Marketing : Concepts, Framework and Consumer Insights, Foundation and Trends in Marketing, Vol.5 No.2, pp. 55-112.

Sharma, R. and Sharma, V. 2011. Pemasaran Berbasis Pengalaman : A Contemporary Marketing Mix, International Journal of Management and Strategy, Vol.2 No.3, pp.27-35.

Siregar, S. 2013. Metode Penelitian Kuantitatif : Dilengkapi Perbandingan Perhitungan Manual \& SPSS, Edisi Pertama. Kencana. Jakarta.

Solomon, M. R. 2011. Consumer Behavior : Buying, Having, and Being, $9^{\text {th }}$ edition. Pearson Prentice Hall. New Jersey.

Suharyadi dan Purwanto, S.K. 2013. STATISTIKA : Untuk Ekonomi dan Keuangan Modern, Edisi 2. Salemba Empat. Jakarta.

Sugiyono. 2013. Metode Penelitian Administrasi. Alfabeta. Bandung.

http://www.cnnindonesia.com/gayahidup/20150210162426-269-31086/surveibandung-kota-terfavorit-wisatawan-se-asean/ http://www.ragamtempatwisata.com/2013/08 /peminat-wisata-bandung-meningkat-50persen.html

http://m.inilah.com/news/detail/2205089/jum lah-wisatawan-ke-bandung-selatanmeningkat

http://www.kompasiana.com/www.inatanaya .com/bandung-kebanjiranhotel_558e7b425fafbd0714744670 http://traveltourismindonesia.com/bisnishotel-di-bandung-pun-tak-terbendung.html 